JKKP: Jurnal Kesejahteraan Keluarga dan Pendidikan

http://doi.org/10.21009/JKKP

DOI: doi.org/10.21009/JKKP.032.04

E-ISSN: 2597-4521

\title{
Pengaruh Dukungan Sosial Keluarga Terhadap Kualitas Hidup Lansia di Panti Werdha Ria Pembangunan J akarta Timur
}

\author{
Dwi Arini ${ }^{1, a)}$, Hamiyati ${ }^{1, b)}$, Tarma ${ }^{1, c}$ \\ a)dwiarinni@gmail.com ,_b)hamiyati32@yahoo.com , c)tarmasae@gmail.com \\ 1Program Studi Pendidikan Kesejahteraan Keluarga, \\ Fakultas Teknik, Universitas Negeri J akarta \\ J I. Rawamangun Muka, J akarta Timur.13220
}

\begin{abstract}
Abstrak
Dukungan sosial serta kepedulian pada Lanjut usia yang diperoleh dari keluarga, kerabat dan masyarakat sangat diperlukan agar lansia tidak mengalami masalah seperti kurang mendapat perhatian dan kasih sayang, merasa kesepian,depresi dan merasa dirinya tidak berguna. Dukungan yang bersumber dari orang-orang terdekat merupakan sistem pendukung bagi lansia untuk dapat terus aktif ditengah keterbatasan yang dialaminya. Penelitian ini bertujuan untuk mengetahui pengaruh dukungan sosial keluarga terhadap kualitas hidup lansia. Penelitian menggunakan metode survei dengan pendekatan korelasi yang dilakukan pada lanjut usia yang tinggal di Panti Werdha Ria pembangunan Cibubur, Jakarta Timur. Penelitian ini dilaksanakan pada bulan maret-mei 2016. Teknik pengambilan sampel pada penelitian ini menggunakan teknik purposive sampling dengan sampel sabanyak 44 orang. Perhitungan statistik pada penelitian ini menunjukkan bahwa dukungan sosial keluarga dan kualitas hidup lansia di Panti Werdha Ria Pembangunan memiliki tingkat kategori kuat. Dukungan sosial keluarga terhadap kualitas hidup lansia menghasilkan nilai korelasi $(0,611)$ yang berarti dukungan sosial keluarga berpengaruh sebesar $37,34 \%$ terhadap terbentuknya kualitas hidup lansia. Kesimpulan dari penelitian ini adalah ho ditolak dengan hasil thitung $(6,350)$. Ttabel $(2,016)$ sehingga ho diterima, yaitu terdapat pengaruh yang signifikan antara dukungan sosial keluarga terhadap kualitas hidup lansia.
\end{abstract}

Kata Kunci : Dukungan keluarga, kualitas hidup, lansia

The Effect of Family Social Support Against Elderly Quality of Life in Ria Pembangunan Home Werdha East J akarta

\begin{abstract}
Social support and concern for Elderly are obtained from family, friends and society is indispensable so that elderly did not experience such problems receive less attention and affection, feeling lonely, depressed and felt useles. The support comes from those closest is the support system for the elderly to be able to continue to be active amid the limitations they experienced. This study aimed to determine the effect of family social support on quality of life of the elderly. The study used survey method with correlation approach conducted in the elderly who stay in Home Werdha R ia Pembangunan C ibubur, East J akarta. This study was conducted in March-May, 2016. The sampling technique in this study using purposive sampling as many as 44 people. Statistical data in this study show that family social support and quality of life of the elderly in Home Werdha Ria Pembangunan Cibubur has a strong category level. Family social support on quality of life of elderly produce a correlation value (0.611), which means that
\end{abstract}


social support affects families of $37.34 \%$ against the formation of the quality of life of the elderly. The conclusion of this study is ho rejected with the result tTest (6.350). Ttable (2.016) it is means ho accepted, that is a significant difference between family social support against elderly quality of life.

Keywords : F amily support, quality of life, elderly

\section{PENDAHULUAN}

Indonesia adalah termasuk negara yang memiliki era penduduk berstruktur lanjut usia (aging structured population) karena jumlah penduduk yang berusia 60 tahun ke atas sekitar 7,18\%. Populasi lansia di Indonesia diprediksi meningkat lebih tinggi daripada populasi lansia di wilayah Asia dan global setelah tahun 2050. Secara global bila dilihat dari struktur kependudukannya berstruktur tua sejak tahun 1950. Sementara Asia dan Indonesia berstruktur tua dimulai dari tahun 1990 dan 2000. Walaupun dikatakan berstruktur tua tetapi jumlah penduduk $<15$ tahun lebih besar dari penduduk lansia (60+tahun), tetapi pada tahun 2040, baik global ataupun dunia, Asia dan Indonesia diprediksi bahwa jumlah penduduk lansia sudah lebih besar dari jumlah penduduk yang berusia $<15$ tahun.

Usia merupakan proses menua pada manusia yang tidak dapat dihindarkan. Menua adalah suatu proses menghilangnya secara perlahan-lahan kemampuan jaringan untuk memperbaiki diri atau mengganti diri dan mempertahankan struktur dan fungsi normalnya sehingga tidak dapat bertahan terhadap lesion atau luka (termasuk infeksi) dan memperbaiki kerusakan yang diderita (Darmojo,2000). Hal itu mengakibatkan secara progresif akan menyebabkan kehilangan daya tahan terhadap infeksi dan makin banyaknya penumpukan distorsi metabolik dan struktural yang disebut sebagai penyakit degeneratif.

Kebanyakan lansia secara biologis pada umumnya belum tentu mampu hidup sendiri dan memerlukan bantuan orang lain untuk membantunya beraktifitas. Hal tersebut dikarenakan fisik lansia yang sudah berkurang salah satunya adalah adanya penurunan masa otot, bahkan tidak sedikit diantaranya sama sekali tidak bisa meninggalkan tempat tidurnya. Oleh sebab itu memelihara atau merawat lansia akan menjadi suatu tantangan besar, bukan hanya memerlukan perhatian dan kasih sayang, juga termasuk waktu, kesabaran, pengertian dan pengetahuan, lingkungan yang sangat mendukung, dan tentu saja keuangan yang memadai, tanpa itu semua keluarga, atau orang yang merawatnya akan mengalami kesulitan.

Kesulitan yang dihadapi tersebut dapat menjadi suatu masalah, dan masalah tersebut dialami oleh banyak keluarga yang memiliki lansia. Panti jompo menjadi salah satu solusinya, karena tidak ingin membiarkan lansia tidak terurus dan terlantar yang disebabkan oleh keterbatasan ekonomi untuk merawat lansia maupun karena kesibukan dari anggota keluarga lansia tersebut yang tidak memungkinkan untuk merawat lansia. Sangat banyak lansia yang dirawat diberbagai panti jompo dengan alasan anak-anak tidak mampu lagi mengurus lansia. Hal ini banyak ditemukan di kota-kota besar. Disamping kaum laki-laki yang bekerja, perempuan pun banyak yang menjadi wanita karir sehingga tidak selalu berada di rumah dan memiliki waktu luang untuk mengurus orangtua yang sudah lanjut usia. Anak-anak yang telah tumbuh dewasa dan mendapatkan pekerjaan yang layak akan menitipkan lansia di panti karena alasan sibuk dengan pekerjaan dan jarang di rumah. Dari sekian banyak kasus penitipan lansia, anak-anak tidak meminta persetujuan lansia terlebih dahulu, lansia biasanya dipaksa untuk tinggal di panti. Lansia yang memiliki pemikiran negatif akan menerima keputusan keluarga yang beranggapan jika masih tinggal bersama keluargamaka akan menyusahkan serta menghambat masa depan anak-anak, sehingga secara langsung anggapan tersebut menimbulkan rasa bersalah yang berlebihan pada diri lansia. 
Di banyak negara memasukkan atau menitipkan orangtua atau kerabat yang telah lansia dipanti jompo sudah menjadi gaya hidup. Negara Indonesia yang masih menjunjung tinggi kekeluargaan, tinggal di panti merupakan sesuatu hal yang tidak natural lagi. Tinggal di rumah masih jauh lebih baik daripada di panti. Namun dibalik fenomena tersebut ternyata banyak manfaat positif yang bisa diperoleh lansia yang tinggal di panti jompo atau panti werdha salah satunya di Panti Werdha Ria Pembangunan, Cibubur, Jakarta Timur. Disana lansia dapat tinggal dengan fasilitas yang baik dan terjamin perawatannya serta berkomunikasi dengan sesama lansia dan masyarakat yang berkunjung ke panti untuk memberikan dukungan sosial berupa perhatian dan kasih sayang untuk menghibur lansia.

Dukungan sosial serta kepedulian pada Lanjut usia yang diperoleh dari keluarga, kerabat dan masyarakat sangat diperlukan dan berguna bagi lansia mengingat di usia senja banyak lansia yang menjauh dari keluarga karena kesibukan anggota keluarganya masing-masing dan hidup sebatang kara serta kurang mendapatkan perhatian dan kasih sayang keluarga, terutama lansia yang tinggal di panti sosial atau panti werdha sehingga tidak sedikit dari lansia tersebut mengalami masalah seperti kurang mendapat perhatian dan kasih sayang, merasakesepian,depresi dan merasa dirinya tidak berguna (useless).Dukungan yang bersumber dari orang-orang terdekat, baik dari anak, keluarga, kerabat maupun masyarakat sangat diperlukan lansia dalam menjalani sisa hidupnya karena merupakan sistem pendukung bagi lansia untuk dapat terus aktif ditengah keterbatasan yang dialaminya. Lansia diharapkan dapat mempertahankan kemandiriannya dan seminimal mungkin memiliki ketergantungan pada orang lain, dengan memberikan dukungan dan merubah perilaku ketergantungan lansia.

Berdasarkan masalah dukungan sosial yang diperoleh lansia dari anggota keluarga yang tinggal di panti werdha, peneliti tertarik untuk mengetahui Bagaimana Pengaruh Dukungan Sosial Keluarga Terhadap Kualitas Hidup lansia di Panti Werdha Karya Bhakti Ria Pembangunan Cibubur, Jakarta Timur.

\section{METODOLOGI PENELITIAN}

Penelitian ini dilakukan di Panti Werdha Karya Bhakti Ria Pembangunan yang beralamat di Jalan karya Bhakti No. 2 Cibubur, Jakarta Timur. Tempat penelitian ini dipilih dengan alasan lokasi yang strategis, data-data mendukung dan sesuai dengan apa yang akan diteliti. Penelitian ini dilaksanakan pada bulan Maret sampai dengan bulan Juli 2016.

Generalisasi yang terdiri atas : objek atau subyek yang empunyai kualitas dan karakteristik tertentu yang ditetapkan oleh peneliti untuk dipelajari dan kemudian ditarik kesimpulannya (Sugiyono, 2008). Populasi penelitian ini adalah seluruh lansia yang berada di Panti werdha Ria Pembangunan yang berjumlah 77 orang dan diambil berdasarkan sampel menjadi 44 orang.

Sampel adalah bagian dari jumlah dan karakteristik yang dimiliki oleh populasi tersebut (Sugiyono, 2014). Jumlah populasi keseluruhan pada penelitian ini tidak memungkinkan.

Metode yang digunakan di dalam penelitian ini adalah survei dengan menggunakan pendekatan korelasional. Menurut Sugiyono (2009), metode survei digunakan untuk mendapatkan data dari tempat tertentu yang alamiah (bukan buatan), tetapi peneliti melakukan perlakuan dalam pengumpulan data, misalnya dengan menyebarkan kuesioner, test, wawancara terstruktur dan sebagainya.

Populasi adalah wilayah peneliti mempelajari semua yang ada pada populasi salah satunya dikarenakan adanya pertimbangan pada karakteristik populasi serta keterbatasan waktu dan biaya.Pada penelitian ini diambil sampel lansia berusia 66-85 tahun dengan jumlah 44 orang.

Teknik sampling yang digunakan dalam penelitian ini adalah Purposive Sampling yaitu tekink yang digunakan peneliti jika peneliti mempunyai pertimbangan-pertimbangan tertentu di dalam pengambilan sampelnya atau penentuan sampel untuk tujuan tertentu. 
Variabel adalah suatu atribut atau sifat atau nilai dari orang, obyek atau kegiatan yang mempunyai variasi tertentu yang ditetapkan oleh peneliti untuk dipelajari dan kemudian ditarik kesimpulannya (Sugiyono, 2014). Variabel independen atau variabel bebas merupakan variabel yang mempengaruhi atau yang menjadi sebab perubahannya atau timbulnya variabel dependen (variabel terikat). Variabel dependen atau variabel terikat merupakan variabel yang dipengaruhi atau yang menjadi akibat, karena adanya variabel bebas (Sugiyono, 2014). Sesuai dengan perumusan masalah yang diajukan bahwa terdapat pengaruh antara variabel $X$ (Dukungan Sosial Keluarga) terhadap variabel Y (Kualitas Hidup Lansia).

Instrumen penelitian adalah suatu alat yang digunakan untuk mengukur fenomena alam maupun sosial yang diamati. Secara spesifik semua fenomena ini disebut variabel penelitian (Sugiyono, 2014) Instrumen yang digunakan dalam penelitian ini adalah kuesioner atau angket. Kuesioner merupakan teknik pengumpulan data yang dilakukan dengan cara memberi seperangkat pertanyaan atau pernyataan tertulis kepada responden untuk dijawabnya (Sugiyono, 2014). Kuesioner yang akan digunakan pada penelitian ini

Setelah dilakukan uji reliabilitas variabel x (dukungan sosial keluarga) diperoleh hasil koefisien reabilitas sebesar 0,852 hasil tersebut masuk dalam kategori reliabilitas yang sangat kuat. Sedangkan uji reliabilitas pada variabel y (kualitas hidup diperoleh hasil koefisien reliabilitas sebesar 0,801 hasil tersebut masuk dalam kategori reliabilitas yang sangat kuat.

Kuesioner tertutup yaitu kuesioner yang sudah disediakan pertanyaan dan jawabannya sehingga responden tinggal memilih. Peneliti menggunakan kuesioner dukungan sosial keluarga dari penelitian terkait dan kuesioner kualitas hidup (WHOQOL- BREF) yang dibuat oleh World Health Organization (WHO):

1. Instrumen Dukungan Sosial

Keluarga

Instrumen ini berupa Skala Likert yaitu skala yang digunakan untuk mengukur sikap, pendapat, dan persepsi seseorang atau sekelompok orang tentang fenomena sosial (Sugiyono, 2014) dengan lima pilihan alternatif jawaban yaitu selalu setuju, sering, kadang-kadang, jarang, dan tidak pernah. Semakin tinggi skor yang didapat, maka semakin baik dukungan sosial keluarga yang diterima lansia.

2. Instrumen Kualitas Hidup

(WHOQOL - BREF )

Alat ukur WHOQOL BREF merupakan alat ukur yang valid $(r=0,89-0,95)$ dan reliable $(R=0,66-0,87)$. WHOQOL-BREF ini berbentuk skala likert 1-5 dengan item pertanyaan berjumlah 26 yang terdiri atas pertanyaan psotif, kecuali pada pertanyaan nomor 3,4,26.

Teknik pengumpulan data yang digunakan pada penelitian ini terbagi menjadi dua, yaitu data primer dan data sekunder. Data primer didapat dari kuesioner yang diisi oleh responden dan data sekunder berupa dokumen tertulis atau gambar dan foto.

\section{HASIL DAN PEMBAHASAN}

Data dukungan sosila keluarga diperoleh melalui pengisian instrumen penelitian yang berupa skala Likert oleh 44 responden lansia di Panti Werdha Ria Pembangunan. Berdasarkan pengolaahan data kuesioner model skala Likert diperoleh skor terendah 58, skor tertinggi 82, dan skor rata-rata sebesar 75,25 . Varians $\left(S^{2}\right)$ variabel Dukungan sosial keluarga sebesar 22,57 dan simpangan baku (S) sebesar 4,75. Deskriptif data dan distribusi frekuensi Dukungan Sosial keluarga terdiri dari rentang skor sebesar 24, banyaknya kelas interval sebesar 7 dan panjang kelas sebesar 4. Selain itu terdapat data yang dihasilkan dan dapat dilihat pada tabel berikut: 
Tabel 1. Distribusi Frekuensi Dukungan Sosial Keluarga

\begin{tabular}{rrrccc}
\hline No. & Interval & $\begin{array}{c}\text { Batas } \\
\text { Bawah }\end{array}$ & $\begin{array}{c}\text { Batas } \\
\text { Atas }\end{array}$ & $\begin{array}{c}\mathbf{F} \\
\text { Absolut }\end{array}$ & F relatif \\
\hline $\mathbf{1}$ & $58-61$ & 57,5 & 61,5 & 1 & $15,2 \%$ \\
$\mathbf{2}$ & $62-65$ & 61,5 & 65,5 & 1 & $22,7 \%$ \\
$\mathbf{3}$ & $66-69$ & 65,5 & 69,5 & 3 & $25,8 \%$ \\
$\mathbf{4}$ & $70-73$ & 69,5 & 73,5 & 7 & $24,2 \%$ \\
$\mathbf{5}$ & $74-77$ & 73,5 & 77,5 & 16 & $7,6 \%$ \\
$\mathbf{6}$ & $78-81$ & 77,5 & 81,5 & 15 & $3,0 \%$ \\
$\mathbf{7}$ & $82-85$ & 81,5 & 85,5 & 1 & $1,5 \%$ \\
\hline \multicolumn{5}{r}{} & Total \\
\hline
\end{tabular}

Berdasarkan tabel distribusi frekuensi pada variabel dukungan sosial keluarga di atas dapat diketahui banyaknya kelas interval sebsar 7 kelas. Frekuensi relatif terbesar berada pada kelas kelima yaitu dengan rentang 74-77 sedangkan jumlah responden sebanyak 16 lansia. Sementara itu frekuensi terendah berada pada kelas kedua yaitu pada rentang 82-85 sebanyak 1 responden.

Hasil dari perhitungan skor perdimensi dari dukungan sosial keluarga yang pertama adalah dimensi pengargaan mendapat presentase tertinggi sebesar 70,73\%, dimensi dukungan emosional sebesar $65,96 \%$, dukungan $65,96 \%$ dukungan terendah yaitu instrumental sebesar 55,2 \%.

Data kualitas hidup lansia diperoleh melalui pengisian instrumen penelitian yang berupa skala Likertoleh 44 responden lansia di Panti Werdha Ria Pembangunan. Berdasarkan pengolaahan data kuesioner model skala Likert diperoleh skor diperoleh skor terendah 60, skor tertinggi 84, dan skor ratarata sebesar 77 . Varians $\left(\mathrm{S}^{2}\right)$ variabel Dukungan sosial keluarga sebesar 29,81 dan simpangan baku (S) sebesar 5,46.

Deskriptif data dan distribusi frekuensi Dukungan Sosial keluarga terdiri dari rentang skor sebesar 24, banyaknya kelas interval sebesar 7 dan panjang kelas sebesar 4 . Selain itu terdapat data yang dihasilkan dan dapat dilihat pada tabel 2 berikut :

Tabel 2. Distribusi Frekuensi Kualitas Hidup

\begin{tabular}{cccccc}
\hline No. & Interval & $\begin{array}{c}\text { Batas } \\
\text { Bawah }\end{array}$ & $\begin{array}{c}\text { Batas } \\
\text { Atas }\end{array}$ & $\begin{array}{c}\mathbf{F} \\
\text { Absolut }\end{array}$ & F relatif \\
\hline $\mathbf{1}$ & $60-63$ & $60-63$ & 63,5 & 3 & $6,8 \%$ \\
$\mathbf{2}$ & $64-67$ & $64-67$ & 67,5 & 1 & $2,3 \%$ \\
$\mathbf{3}$ & $68-71$ & $68-71$ & 71,5 & 1 & $2,3 \%$ \\
$\mathbf{4}$ & $72-75$ & $72-75$ & 75,5 & 5 & $11,4 \%$ \\
$\mathbf{5}$ & $76-79$ & $76-79$ & 79,5 & 19 & $43,2 \%$ \\
$\mathbf{6}$ & $80-83$ & $80-83$ & 83,5 & 14 & $31,8 \%$ \\
$\mathbf{7}$ & $84-87$ & $84-87$ & 87,5 & 1 & $2,3 \%$ \\
\hline
\end{tabular}

frekuensi pada variabel Kualitas Hidup di atas dapat diketahui banyaknya kelas interval sebsar 7 kelas. Frekuensi relatif terbesar berada pada kelas kelima yaitu dengan rentang 76-79 sedangkan jumlah responden sebanyak 19 lansia. Sementara itu frekuensi terendah berada pada kelas kedua yaitu pada rentang 64-67 sebanyak 1 responden. 
Hasil dari perhitungan skor perdimensi kualitas hidup yang pertama adalah dimensi hubungan sosial yang mendapat presentase tertinggi sebesar $85,79 \%$, dimensi psikologis sebesar $81,02 \%$, dimensi lingkungan $78,16 \%$, dan terendah yaitu kesehatan fisik sebesar $73,86 \%$.

\section{KE SIMPULAN}

Berdasarkan dari hasil penelitian yang telah dilakukan oleh peneliti, maka dapat disimpulkan sebagai berikut:

1. Terdapat pengaruh positif signifikan antara Dukungan Sosial Keluarga dimana nilai $r=0,611$ yang berarti memiliki korelasi yang kuat, sehingga Dukungan Sosial Keluarga yang diperoleh lansia dari anggota keluarganya menjadi salah satu solusi alternative dalam meningkatkan kualitas dan harapan hidup lansia yang tetap baik.

2. Perhitungan analisis statistik pada penelitian ini menyatakan $37,34 \%$ variabel dukungan sosial keluarga memberikan kontribusi terhadap kualitas hidup lansia, sedangkan sisanya $62,66 \%$ dipengaruhi oleh faktor-faktor lain selain dukungan sosial itu sendiri. Maka dari itu terdapat pengaruh positif yang signifikan antara Dukungan Sosial Keluarga Terhadap Kualitas Hidup Lansia di Panti Werdha Ria Pembangunan.

3. Dukungan sosial yang paling mempengaruhi kualitas hidup lansia dari indikator keseluruhan yaitu penghargaan positif, persetujuan gagasan, bantuan berupa tindakan, kasih sayang, empati,perhatian, nasehat, saran petunjuk.

\section{SARAN}

Berdasarkan hasil penelitian yang dilakukan peneliti pada lansia dalam hal dukungan sosian sosial keluarga, peneliti menyarankan agar:

1. Keluarga yang menitipkan orangtua, atau saudara yang sudah berusia lanjut di panti werdha agar diharapkan dapat lebih menjaga perasaan lansia, memberikan perhatian penuh dan sering menjenguk lanisa pada saat hari libur. Karena lanisa sangat membutuhkan dukungan dari keluarganya agar dirinya merasa berharga, berguna dan tidak merasa kesepiaankarena keluarganya peduli akan keberadaannya.

2. Peneliti selanjutnya disarankan agar dapat melanjutkan penelitian dengan lebih luas dan mendalam tentang faktor-faktor lain yang berhubungan dengan dukungan sosial dengan kualtas hidup lansia. Sehingga hasil penelitiannya dapat dipergunakan untuk memperkaya khasanah ilmu pengetahuan.

\section{DAFTAR PUSTAKA}

Darmojo, B.2002. Buku Ajar Geriatri. Fakultas Kedokteran Universitas Indonesia. Jakarta Hartati K, dkk. 2004. Translation the World Health Organization Quality of Life (WHOQOL)- BREF. Sugiyono. 2008. Metode Penelitian Administrasi. Alfabeta. Bandung

Sugiyono. 2009. Metode Penelitian Kuantitatif dan Kualitatif. Alfabeta. Bandung

Sugiyono. 2012. Metode Penelitian Pendidikan. Alfabeta. Bandung.

Sugiyono. 2014. Metode Penelitian Pendidikan Pendekatan Kuantitatif, Kualitatif, dan R\&D. Alfabeta.

Bandung 